\title{
The Epistemology of Theistic Philosophers' Reactions to the Problem of Evil
}

\author{
Bryan Frances \\ Forthcoming in \\ American Catholic Philosophical Quarterly
}

\begin{abstract}
I first argue that contrary to many atheistic philosophers, there is good reason to think the typical theistic philosopher's retaining of her theism when faced with the Problem of Evil (PoE) is comparatively epistemically upstanding even if both atheism is true and the typical theistic philosopher has no serious criticism of the atheist's premises in the PoE argument. However, I then argue that contrary to many theistic philosophers, even if theism is true, the typical theistic philosopher has no good non-theistic reasons for rejecting any of the atheist's premises, and she has good non-theistic reasons in favor of the atheist's premises. In that respect it's extremely difficult for the theistic philosopher to respond to the PoE in an informative, non-question-begging way. I close by considering whether theistic philosophers should reject my second thesis. ${ }^{1}$
\end{abstract}

\section{Skepticism about the Epistemic Quality of Theistic Reactions to the Problem of Evil}

It's fair to say that many philosophers occasionally have dim views regarding the philosophizing of some other philosophers. You might think your colleague, a metaphysician, has some grand metaphysical convictions that are only borderline rational. Or, you might think that your friend the epistemologist is irrational in his adamant dismissal of radical skepticism. Many philosophers think error theorists of various kinds are philosophizing quite poorly when they defend those error theories. You might suspect your theistic colleague is irrational, or at least epistemically subpar, in how she responds to the problem of evil (PoE). Part of what makes the latter case interesting is that your colleague's theism may well be at least partially based on allegedly epistemically powerful but private inner experiences, ones she thinks put her in some sort of contact with God.

I'm interested in the general issue of the epistemology of one's retaining belief in a claim after encountering arguments against that claim-arguments that are considered, by the relevant community, to be powerful challenges to that claim. As an interesting test case, this essay examines the epistemology of competent contemporary theistic philosophers' reactions to the PoE.

1 This research is supported by the programme Mobilitas Pluss project MOBTT45 and the Centre of Excellence in Estonian Studies (European Regional Development Fund) and is related to research project IUT20-5 (Estonian Ministry of Education and Research). 
We first need to have a fairly good version of the (evidential) PoE before us. There are several versions to choose from, but I will use this one:

Claim (a): There has been, spread out over the centuries, a large group of people who are highly intelligent, who know an enormous amount about suffering and its potential moral justification, who have spent a great deal of time (centuries collectively) thinking very hard about the justification of suffering, and who have undertaken a very long (again, centuries), intelligent, heartfelt, and otherwise serious search for goods or facts or reasons or whatnot that justify suffering. ${ }^{2}$

Claim (b): These people have collectively failed to find justification for an enormous number of instances of suffering. That is, there is an enormous number of instances of suffering $\mathrm{S}$ such that these people have collectively failed to come to know any highly informative truth of the form 'The justification for $\mathrm{S}$ is such-and-such'.

Claim (c): If there has been spread out over the centuries, a large group of people who are highly intelligent, who know an enormous amount about suffering and its potential moral justification, who have spent a great deal of time (centuries collectively) thinking very hard about the justification of suffering, and who have undertaken a very long (again, centuries), intelligent, heartfelt, and otherwise serious search for facts or reasons or whatnot that justify suffering, and they have collectively failed to find them for an enormous number of instances of suffering, then for at least one instance of suffering there were no such goods or facts or reasons or whatnot to be found.

From (a)-(c) it follows that there is an instance of suffering that has no justification. (Claim (c) is a material conditional.)

Claim (d): If there is an instance of suffering that has no justification, then God does not exist.

Claim (e): God exists.

The collection of those five claims is logically inconsistent. Most any philosopher will accept (a), as it's an obvious historical fact. So, we conclude that the falsehood(s) is (are) in (b)-(e). The philosophers who remain theists - the subjects of this essay-retain belief in (e) and think that the conjunction of (b)-(d) is false. Naturally, many atheists think that the evidence for the conjunction of (b)-(d) is quite a bit stronger than the evidence for (e), and as a consequence they think the argument is quite powerful against theism. And as suggested above, they often think that theistic philosophers are not responding epistemically well to the PoE.

\footnotetext{
${ }^{2}$ There are several reasonable and approximately precise ways to fill out 'instance of suffering $\mathrm{x}$ is morally justified'. In the above claims I intend to implicitly quantify over precisifications that are both pertinent and reasonable. In section 3.1 I make few remarks on this issue.
} 
Contrary to the atheists, I think there is good reason for thinking that responding to (a)-(e) in an epistemically reasonable fashion is fairly common for competent contemporary theistic philosophers even if theism is false. Plantinga (2000) would argue that theists are warranted in retaining (e) and rejecting the conjunction of (b)-(d) if theism is true. I'm considering a stronger thesis: even if theism is false the typical theistic philosopher's retaining of (e) is epistemically upstanding. But contrary to the theists, I think that in another epistemic respect their response to the PoE is quite poor. I argue that it is extremely hard to find good non-theistic reasons for rejecting the conjunction of (b)-(d) even if theism is true; in that sense responding to the PoE in an epistemically upstanding, non-questionbegging, theistic manner is just about hopeless.

For the competent contemporary theistic philosopher the situation is a bit like the following. I know that at least one of 'It will rain on 15 May two years hence in Chicago' and 'It will not rain on 15 May two years hence in Chicago' is false, but I have no serious evidence against either, taken individually. Hence, there are two claims such that I know one is false but I have no serious evidence against either, taken individually. Somewhat similarly-but not exactly-the (competent contemporary) theistic philosopher can (in the present time of the actual world) have good overall theistic reason to think that at least one of (b)-(d) is false even though she has no serious non-theistic evidence against any one of them, taken individually.

This is not an essay on the PoE. As such, I will not be even attempting to find the falsehood(s) in (a)(e), although I'll offer a few comments on them below (especially (b) and (c)). My focus is the epistemology of competent contemporary theistic philosophers' reactions to the PoE. The more general issue, of which this is a particularly interesting test case, is the epistemology of controversial belief (my 2008a, 2008b, 2010, 2012, 2013b, 2014, 2018a, 2018b, 2018c, 2019).

\section{Why Responding to the Problem of Evil is Easy}

When figuring out what to think about (b)-(e), after she has concluded that at least one of those four claims has to be false, the competent contemporary theistic philosopher will typically do two things.

First, she will admit that there is at least some good reason to accept each of (b)-(d), taken individually (and as mentioned above she admits that (a) is true). After all, no philosopher is going to spend perhaps years investigating a logically valid argument against her own view if she thinks there is no good reason whatsoever to think the premises are true; at the very least, her knowledge that a great many competent philosophers think that the argument is sound will provide her with significant if inconclusive evidence that there are good reasons for those premises. Of course, given that she is eventually going to retain belief in (e), and she has already admitted that the conjunction of (b)-(e) is false, she also holds that the conjunction of (b)-(d) is false. But that's obviously consistent with holding that there is good reason for each conjunct. For instance, she may well eventually come to the view that the overall evidence for one of (b)-(d) is quite poor, even though there is some good evidence for it.

This scenario has nothing in particular to do with theists or the PoE. The above description applies to virtually every philosopher who encounters what she considers a valid argument against one of her views, an argument that is well worth investigating in detail since it amounts to a serious objection to 
her view. For instance, even someone who rejects skepticism will admit that there is good reason to accept each of the following claims, taken individually:

1. If you know that you have two hands, then you can know that you aren't a mere brain in a vat being fed electrical signals to give you the illusion of having a full body and a normal life.

2. If you can know that you're not a mere brain in a vat, then there is something that rules out for you the scenario in which you're a mere brain in a vat.

3. There isn't anything that rules out that BIV scenario for you.

4. Hence, you don't know that you have two hands.

The non-skeptical epistemologist who spends a good portion of her career responding to skepticism rejects (4) but typically admits both that the argument is valid and there is good reason to accept each premise, taken individually. I'm saying that an analogous point holds for the theist and the PoE.

Second, and more importantly, the typical theistic philosopher will come to think E>B-D: her overall evidence for (e) is significantly stronger than that for at least one of (b)-(d). ('Evidence' has to be understood broadly here; many "reformed" epistemologists would insist we use 'warrant' instead because of the partially experiential source for (e).) For instance, many typical competent contemporary theistic philosophers will say that their evidence for (e) is stronger than their evidence for (c) (so never mind (b) or (d), she thinks).

On the basis of this judgment in favor of E>B-D she does two things: (1) concludes that the falsehood amongst (b)-(e) is one (or more) of (b)-(d), and (2) retains belief in (e). I assume that this is a typical theistic response to the PoE (and it has similar variants for other good versions of the PoE).

The temporal order of these events is not terribly important. The main point is that the typical theistic philosopher will realize that the conjunction of (b)-(e) is false, consider the evidence she has for each conjunct, judge that the overall evidence for (e) significantly exceeds that of at least one of (b)-(d), and partly on the basis of the judgment retain her belief in (e).

Clearly, in almost all realistic cases she will not have any theory, mathematical or otherwise, of evidence (or justification or warrant). If asked question $Q$, 'What exactly do you mean when you say your evidence for (e) is "stronger than" your evidence for (c)?' she will probably say that she isn't sure, and that $Q$ is an open question in epistemology. My claim here is that the typical theistic philosopher will say that her evidence for (e) is stronger than her evidence for (c), or perhaps (b). I am not saying, and for the purposes of my argument have no burden to say, what the correct answer to $Q$ is. Likewise, the theistic philosopher need not have any answer to $Q$ in order to be reasonable in her reaction to the PoE. More specifically, she need not know or have any solid belief regarding the correct analysis of ' $M y$ evidence for $X$ is stronger than my evidence for $Y$ ' in order to have a reasonable belief that her evidence for $\mathrm{X}$ is stronger than her evidence for $\mathrm{Y}$.

Here is a two-part thesis regarding this typical response of the theistic philosopher to the PoE: 
$\mathbf{T}$ : The contemporary philosopher who starts out believing (e), sees that the conjunction of (a)-(e) is inconsistent, accepts that (a) is true and hence that the conjunction of (b)-(e) is false, can, at the present time in the actual world, be comparatively epistemically upstanding in (1) coming to believe $E>B-D$ and (2) retaining belief in (e).

The terms 'contemporary', 'in the actual world', and 'at the present time' are included to emphasize the application to today's theistic philosophers, and not merely possible or cognitively distant philosophers.

Thesis $\mathbf{T}$ is circumspect. Specifically:

- T does not say that the theist needs to upstandingly judge the evidence for (e) to have come in first place in the evidence contest amongst (b)-(e) in order to upstandingly stick with (e). In order to be epistemically upstanding in retaining (e) it is sufficient (I don't say necessary) that she upstandingly judge the overall evidence for (e) to significantly exceed that for at least one of (b)-(d).

- T does not say that the theist is upstanding in concluding that (c), for instance, is false.

- T does not say that the theist's reaction to the PoE (viz. (1) and (2) of T) is "maximally" epistemically good, whatever that might mean.

- $\mathbf{T}$ does not say that there is no epistemically better reaction for her to have (such as suspending judgment on each of (b)-(e)).

- T does not say anything about what she would or should do if she came to think the strength of her overall evidence for (e) was lower than each of that for (b)-(d) but higher than that for the conjunction of (b)-(d).

We cannot start evaluating $\mathbf{T}$ until we get straight on its use of 'comparatively epistemically upstanding'.

When $\mathbf{T}$ says that the competent contemporary theistic philosopher's reaction to the PoE is "comparatively epistemically upstanding" the following claim is intended: in forming/retaining her belief she is about as epistemically justified as philosophers typically are in their philosophizing. So, being epistemically "upstanding" does not mean outstanding, in the sense of being far superior to most other cases of philosophizing. Neither does it mean epistemically justified. Again, it's a comparative claim only. This restriction to comparative justification does not vacate $\mathbf{T}$ of interest, however, since as was pointed out above a typical criticism of theistic philosophers is that they are reacting poorly to atheistic arguments-and by 'poorly' it is often meant that their reaction isn't up to snuff compared to how philosophers generally react to criticisms of their philosophical views.

I am not going to defend the truth of T. I do not claim it's true. Instead, my arguments in the rest of this section are intended to show two things: there is more reason to accept $\mathbf{T}$ than most contemporary non-theistic philosophers think (section 2.1), and the key objections typically leveled against $\mathbf{T}$ are no good (section 2.2). Overall, then, I think we should conclude that we have good reason to believe $\mathbf{T}$ and no good reason to disbelieve it. 
Then in the rest of the essay I switch sides, so to speak, and argue against the theistic philosopher: I argue that even if theism is true, (i) theistic philosophers have no good non-theistic reasons to doubt any of (b)-(d), and (ii) theistic philosophers have good non-theistic reasons to accept each of (b)-(d).

\subsection{Basing Belief in E>B-D on Spiritual Experiences and Testimony}

If theists have spiritual experiences that really are of God, and if the experiences are epistemically strong enough, then those theists probably can be epistemically upstanding in coming to believe E>B$D$, viz. that the overall evidence for 'God exists' is not only strong but significantly stronger than that had by at least one of (b)-(d) (especially (c)). The main reason for this claim is that (1) their evidence for (e) can be extremely strong, and (2) their evidence for (c) is not so strong-even though it is considerable! I will discuss (c) in detail in section 3.

Many philosophers will claim that the vast majority of theists who think they have experienced or perceived God don't actually have experiences or perceptions that are genuinely of God. The atheists will believe this for the obvious reason, but many theists will believe it too even if they are convinced that a lucky few people get "zapped" by God in an extraordinary manner that generates deep knowledge of God. Hence, these critics are happy to accept the conditional claim of the first sentence of the previous paragraph but they object that the antecedent is rarely if ever true (that is, at least one of its two conjuncts is false). More specifically, they hold that even if T1 is true, its 'provided' clause is rarely satisfied and $\mathbf{T} \mathbf{2}$ is false:

T1: The contemporary philosopher who starts out believing (e), sees that the conjunction of (a)(e) is inconsistent, accepts that (a) is true and hence that the conjunction of (b)-(e) is false, can, at the present time in the actual world, be comparatively epistemically upstanding in (1) coming to believe E>B-D and (2) retaining belief in (e)-provided she has had spiritual experiences that really are of God and those experiences are epistemically strong.

T2: The contemporary philosopher who starts out believing (e), sees that the conjunction of (a)(e) is inconsistent, accepts that (a) is true and hence that the conjunction of (b)-(e) is false, can, at the present time in the actual world, be comparatively epistemically upstanding in (1) coming to believe E>B-D and (2) retaining belief in (e)-even if she has not had spiritual experiences of God.

Against these critics, I think there are (at least) nine facts that collectively make thesis T2 more reasonable than most non-theistic philosophers think-which is not to say that they conclusively show that $\mathbf{T} \mathbf{2}$ is true. Since we have already accepted $\mathbf{T 1}$, my defense of $\mathbf{T} \mathbf{2}$ is a defense of the reasonability of T itself, which was my task. ${ }^{3}$

\footnotetext{
${ }^{3}$ The nine facts focus mostly on matters connected to religious experience. This is not to say that no other facts, having to do with philosophical arguments for instance, might contribute to the defense of T2. I focus on my selected nine facts because I think that for most contemporary theistic philosophers, the nine facts form most of the actual epistemic basis for their coming to believe E>B-D and retaining belief in (e).
} 
First, competent contemporary theistic philosophers sometimes have sequences of religious experiences that are emotionally and intellectually staggering and that overwhelmingly seem to them-even after highly intelligent, informed, and sustained reflection-to be connected to God in some intimate fashion. Non-theists inevitably don't come to grips with this fact (e.g. I certainly didn't for many years). The idea that there is no divine mind on the other end of the experiences in question is almost as implausible, to the experiencers, as the idea that there is no human mind on the other end of their experiences had while interacting with other humans.

Second, much more often theistic philosophers have other religious experiences that are considerably calmer but once again seem to them, even upon competently reflecting on the doubts about the veridicality of religious experience, to have come from God. ${ }^{4}$ Even if the experiences are in fact delusions, they certainly don't seem that way at all to the experiencers, before or after competent reflection.

Third, these theistic philosophers are aware of the enormous amount and variety of testimony from people with epistemically impeccable credentials that says people have epistemically powerful experiences actually of God. (The difference between this fact and the first two facts is this one is testimonial while the other two were experiential.) To see this, recall that we hear, over and over, from a great many disparate sources many of whom have unimpeachable epistemic credentials, stories of God communicating to people in all sorts of private ways, some of which are low-key and others that are experientially spectacular. Theistic philosophers typically admit that a great many people have acquired or sustained their belief in divine-human communication through irrational means such as mental illness, wishful thinking, fear (e.g., of the unknown), groupthink, the strong tendency for obedience and/or submission, and the often unconscious desire for comforting worldviews. For my own part (although I am not a theist), I would guess the number of such sad cases is in the billions. But theistic philosophers also know that a great many other testimonial sources show no signs at all of such factors. To begin with, note that many millions of people claim to have spiritual experiences of God-ones they implicitly take to generate significant warrant for theistic beliefs. People have been making that claim for centuries, and to all appearances an enormous number of them have been critical thinkers who were sincere, intelligent, sane, and no more gullible than the atheists or agnostics. The odds are that you are like me in being personally acquainted with multiple philosophers who satisfy those conditions and who are fully aware of and have carefully considered over a considerable length of time the reasons for doubting the veridicality of experiences of God. Theistic philosophers know that the argument from 'Hundreds of millions of people think there are genuine experiences of God' to 'So, there are genuine experiences of God' is awful, of course, but that hardly matters. The testimonial case for E>B-D is not so decrepit.

Fourth, these theistic philosophers know that it's not as if all these religious experiencers had some bad pizza and subsequently hallucinated God. They know that in many cases there is no strong evidence of obviously non-theistic origins to the experiences.

\footnotetext{
${ }^{4}$ For extensive discussion of the varieties of religious experience/perception, see Alston 1991a.
} 
Fifth, they know that the experiences are not mere one-off events: for many people who have had religious experiences, there was a sequence of theistic spiritual experiences over a long period of time (again with no obvious signs of delusion, irrationality, or other epistemic deficits), which further supports the idea that the experiences are not delusory.

Sixth, they know that the experiences are not the merely emotionally nourishing ones we occasionally have from seeing great natural beauty or artistic excellence. They are more than that, seeming to require a supernatural element. Neither are the experiences in question silly ones such as those that sometimes lead people to say things such as, 'I now realize God is looking out for me; otherwise I wouldn't have survived that car crash'.

Seventh, the theistic philosophers are aware of, and reflect competently on, the reasons to be skeptical about the alleged theistic veridicality of theistic religious experiences.

Eighth, they have professionally competent rebuttals to those reasons. By 'professionally competent' I mean a comparative claim: the rebuttals are about as strong as the rebuttals philosophers typically give to other philosophical arguments against their philosophical views. So, this is not to say that their rebuttals reach the heights of public refutations; rebuttals in philosophy rarely do.

Ninth, theistic philosophers are aware of the enormous amount and variety of testimony from people with epistemically impeccable credentials that says God exists. Obviously, the third and ninth facts overlap.

\subsection{Objector One and My Reply}

The first objector to T2 (and hence T) says that given three facts that I will articulate below, the theistic philosopher usually doesn't come to believe E>B-D in a manner as epistemically good as philosophers typically acquire other philosophical beliefs-even if there really is an actually available route to such epistemically upstanding belief. That is, this objector is saying that even if $\mathbf{T 2}$ is true, the actual basis for the typical theistic philosopher's belief in E>B-D is an epistemically poor one, so T2's truth doesn't have the applicability one might have thought it has. Here are the three alleged facts:

Fact F1: The belief in (e) is typically a highly personal and life-defining belief, which significantly increases the odds that one does not react epistemically well to challenges to it (such as the challenge of the PoE).

Fact F2: Many theists are utterly unable to find any significant weakness in any of (b)-(d) despite holding that the conjunction of (b)-(d) is false. To be sure, they often think they have found such weakness, but they really haven't.

Fact F3: Theists often believe that E>B-D is true and conclude that the conjunction of (b)-(d) is false independently of even attempting to find fault with (b)-(d). They take themselves to not even need to find any fault with (b)-(d) in order to accept E>B-D and retain (e). Instead, they immediately suppose that their evidence/warrant for (e) is stronger than that for at least one of (b), (c), or (d) and then retain (e) and conclude that the conjunction of (b)-(d) is false. 
I will admit for the sake of argument that F1-F3 are true. (I will be arguing for a restricted variant of F2 applied to (c) in section 3.) However, I will argue that the conjunction of F1-F3 casts no significant doubt on $\mathbf{T 2}$ (or T).

With regard to F1, I have a three-part reply. First, I admit that theistic philosophers sometimes let their theistic convictions warp their philosophizing in epistemically bad ways-especially with the PoE. Surely it is uncontroversial that there are at least some theistic philosophers who are dismissive and close-minded, in an epistemically bad way, in instantly thinking that it's obvious that any new (or old) argument against theism (PoE or other) is mistaken, it is a waste of their own time to address the argument, and someone else can carry out the tired duty of spotting the mistakes in arguments for atheism.

But second, I think the sad truth is that the same is true of a great many non-theistic philosophers with regard to certain portions of their philosophizing. Believers in abstract objects often don't react well when faced with arguments for nominalism; believers in formal approaches to the semantic paradoxes often do the same when confronted with wholesale criticisms of such approaches; many epistemologists react in a subpar manner when faced with the prospect of taking radical skepticism as a real possibility, one that might be true; many scientifically oriented philosophers react relatively poorly when other philosophers endorse theses obviously inconsistent with the speculations of theoretical scientists (e.g. quantum gravity); a great number of philosophers are so epistemically allergic to philosophical theories that go against common sense that they dismiss them in an epistemically subpar manner. This unhappy list could be extended in such a way as to cover almost every philosopher! Hence, even if some theistic philosophers respond to the PoE in a way epistemically worse than how they respond to other arguments against views of theirs that are less personal, that merely makes them exactly like non-theistic philosophers responding to criticisms of their more treasured views.

Third, and most importantly, in a great many cases there is no good reason to think the theistic philosopher's response to the PoE (including her endorsement of $E>B-D$ ) is epistemically subpar compared to their responses to criticisms of their other, non-theistic, philosophical views. This was the import of the previous section, with its nine facts: even though F1 is true, the other nine facts exist as well and the latter outweigh the former. What is going on with these competent contemporary theistic philosophers is this: they genuinely and upstandingly think that they have an enormous amount of evidence for (e) (as I mentioned earlier, 'evidence' has to be understood broadly here); they next see that the PoE poses a serious challenge to (e); but then they think to themselves, 'Although the evidence for each of (a)-(d) may seem impressive, the evidence for (e) is so great that it definitely surpasses that for (c) for instance'. A critic might think that the theist has erred in thinking that her evidence for (e) is so strong. However, again, it's just an empirical fact that a great many fully competent, highly reflective philosophers who have those experiences and testimony regarding such experiences continue to hold that the experiences generate excellent evidence for (e)-and they hold this view even after they have reflected well on the reasons to be skeptical about the theistic import of those experiences. There is just no sign of any epistemic deficit in their position-even granting, as I did in the first part of my reply to the objection based on F1, that some theistic philosophers do respond to the PoE in an epistemically subpar fashion. 
With regard to $F 2$ and $F 3$, one must realize that when faced with an obviously valid argument against one's belief it is occasionally epistemically upstanding-even to a high standard-to respond by sticking with that belief, concluding that there must be something wrong with the argument against it, and yet throwing up one's hands and declaring that one can't find the flaw. All of us do this-even philosophers in their philosophizing! There are many cases in which the belief retaining move is epistemically reasonable. So just because the theistic philosopher is faced with the valid argument (a)(d) against (e), and she has not, or maybe even cannot, find fault with any of its premises, this does not automatically mean that she is not epistemically upstanding in sticking with (e).

For instance, it is easy to construct clever mathematical "proofs" for all sorts of obviously false claims, such as, famously, 'The sum of the positive integers is $-1 / 12^{\prime} .{ }^{5}$ When faced with such "proofs", it is epistemically reasonable for people without mathematical training to stick with their old belief 'The sum of the positive integers isn't $-1 / 12$ ' even if they can't find any flaw in the "proof".

This phenomenon is not restricted to mathematics: we do it in philosophy as well. For instance, a great many philosophers are so confident in the truth of certain claims that they will dismiss arguments against them even without any serious investigation of those arguments. If a metaphysician or philosopher of physics offers an argument that I don't have a brain (because of strange facts about composition or physics), well, so much for her argument: I know it's unsound-either invalid or including false premises-even before I evaluate it.

Some of these philosophers have this attitude regardless of the kind of argument involved; others restrict their dismissal to philosophical arguments. The latter philosophers will not dismiss out of hand obviously empirical arguments coming from our best scientists. If large number and percentage of scientists with the relevant expertise argue that $\mathrm{C}$ is false, where $\mathrm{C}$ is a claim that is held with extremely high confidence in everyday life, these philosophers won't reject the scientific arguments merely because they themselves are extremely confident in C. But when they encounter what they judge to be a philosophical argument that goes radically against common sense, then they will retain their commonsensical belief and conclude that the philosophical argument is unsound-and they will do this independently of finding fault in the argument (which is not to say that they take themselves to have failed to find such fault). For instance, think of the philosophical arguments against common sense generated from the sorites, liar, and material composition paradoxes.

Something similar applies to the theist who confronts the PoE. She is faced with a set of individually plausible yet collectively inconsistent claims: (a)-(e). She can see that at least one of them has to be false. She has already decided that (a) is true; so she concludes the falsehood is in (b)-(e). If she reasonably believes that her evidence/warrant for (e) is significantly better than her evidence/warrant for at least one of (b)-(d), then she is reasonable in sticking with (e)-and she can make that cognitive move here even if she has not found fault in (b)-(d).

\footnotetext{
${ }^{5}$ Incredibly, the example isn't fictional. See http://skullsinthestars.com/2014/01/18/infinite-seriesnot-quite-as-weird-as-some-would-say/.
} 
This is not to say that the evidence/warrant for (e) is as strong as the evidence/warrant for the commonsensical claims inconsistent with the anti-commonsensical theories associated with, for instance, the sorites, liar, and material composition paradoxes. But it suffices to show that the objection based on F2 and F3 fails.

\subsection{Objector Two and My Reply}

The second objector to $\mathbf{T 2}$ (and hence $\mathbf{T}$ ) appeals to the epistemology of disagreement: since competent contemporary theistic philosophers are aware that a large number and percentage of philosophers hold that spiritual experiences do not generate strong evidence for (e) (or for $E>B-D$ ), it is not epistemically upstanding for those theistic philosophers to retain their belief in $E>B-D$ in the face of such awareness of disagreement (see my works listed in the bibliography).

In response, note first that the numbers and percentages are crucial here. For instance, suppose the metaphysicians such as van Inwagen (1990) who say there are no non-living composite material objects are right that we don't veridically experience rocks (because there are none to veridically experience). Suppose further that you're a philosopher who is aware of the basis of their ontological view but who rejects it-a very common situation, to be sure. Your retaining your experience-based belief 'There are three rocks over there' is epistemically blameless despite the fact that your belief is false and you are aware of the reasons that go against your belief (reasons that even advocates will admit are not conclusive). The mere fact, which you're aware of, that a few experts disagree with you is hardly enough to make your retaining of your belief epistemically blameworthy; if it was enough, then virtually all the interesting beliefs we care about would end up blameworthy! (E.g. your belief that climate change is going to be bad, would be blameworthy.) Hence, just because you are aware of a few experts who disagree with you does not mean that you fail to be epistemically upstanding in sticking with your belief.

Now, if you knew that $80 \%$, say, of a large group of experts disagreed with your belief-so it's a lot more than "a few" and it's also statistically significant-then you probably would be blameworthy in retaining that belief after finding out the $80 \%$ figure for experts. For instance, if you find out that $80 \%$ of doctors endorse $\mathrm{P}$, and you know that $\mathrm{P}$ is part of the expertise of doctors but virtually no one else, then your prior belief in not-P probably should not be retained, given that you also know that you're no expert on P. But that's not the situation here with the nearly nihilist ontology of composition, as the percentage is nowhere near that high.

The second objector is wise to press the point that not just a few but the clear majority of philosophers think that theistic religious experience is delusional, so the $80 \%$ case from the previous paragraph is at least relevant. However, there are two major problems with the objection.

First, theistic philosophers have little reason to consider the atheist and agnostic philosophers experts on the evidential value of religious experience. For one thing, almost none of them claim to have had anything even remotely similar to such experiences, and it's reasonable to think one can't be an expert on the evidential value of experiences when one hasn't had anything like them. 
Second, most of these non-theistic philosophers have not seriously investigated the evidential value of religious experience, and as a consequence aren't really experts on it. Hence, their opinions are not nearly as epistemically powerful as in the doctor case described a couple paragraphs back. For an enlightening comparison, note that the vast majority of experts on vagueness accept the existence of sharp cutoffs in the truth conditions of ordinary sentences as used in ordinary contexts (whether the cutoffs are epistemicist, supervaluationist, contextualist, etc.). The believers in sharp cutoffs are epistemically upstanding in retaining their belief even though they know full well that the consensus amongst philosophers in general-who are not experts on vagueness-is definitely in opposition. So even though the clear majority of philosophers disbelieve in sharp cutoffs (or that $E>B-D$ ), awareness of this socio-epistemic fact doesn't make one fail to be epistemically upstanding in continuing to think they are wrong.

\subsection{Objector Three and My Reply}

The third and final objector to T2 and T insists that a "fully informed" philosopher would not be epistemically upstanding in believing E>B-D because being so informed would mean she knows that certain facts about religious experience show that such experiences do not justify belief in theism. However, I claim that one can be a competent contemporary theistic philosopher and reasonably deny or otherwise fail to believe the alleged "facts about religious experience" the objector alludes to. A competent contemporary theistic philosopher might reasonably deny or otherwise fail to believe the alleged facts in any of four ways:

- One has not heard of them.

- One has heard of them but not the positive evidence for them.

- One has heard of them as well as the positive evidence for them but upstandingly judges the positive evidence to be inadequate for belief in them.

- One has heard of them, judges the positive evidence for them to be strong, but is also unfortunately aware of contrary misleading evidence and upstandingly but mistakenly judges the contrary evidence to be at least comparable in strength to the positive evidence.

I think the third option is typical: many theistic philosophers are familiar with the criticisms of the epistemic strength of theistic religious experience but don't think they are very good. ${ }^{6}$ I will give just one example:

One common criticism of the epistemic strength of theistic religious experience has two parts. First, there is the claim that a great many theistic religious experiences have contents that closely match the prior religious beliefs of the person having the experience. Second, there is the claim such a fact is excellent reason for concluding that such matching experiences are non-veridical. "You only experience what you've been brainwashed to experience," is one fairly unkind way to put it. In response, let us suppose that the critic is right in the first part of her criticism, so in a great many cases

\footnotetext{
${ }^{6}$ This response can be modified so as to respond to the objection that if there were available a putatively successful logical argument from the evil, this would undercut my thesis $\mathbf{T}$.
} 
a believer's theistic religious experiences match what she has been told might happen if God were to contact her. Of course, one explanation of this matching fact is that such experiences are illusions partially concocted by her own mind, her prior religious beliefs playing a formative role. That fits with the second part of the criticism. But another, quite plausible, explanation of the matching fact is this: God chooses to reveal himself in ways the believer will recognize. Indeed, it is highly reasonable even for a non-theist (such as myself) to suppose that if God reveals himself to people, then he will do it in ways people will recognize, which could easily mean he does so in accordance with their familiar religious tradition. There is more to be said about this criticism and the response to it, of course, but the easy inference from the alleged matching fact to 'those religious experiences were non-veridical' is no good (that is: even if we buy the first part of the criticism, there isn't much reason to accept the second).

In order for the alleged "facts about religious experiences" that allegedly show that theistic religious experience is delusional or otherwise fails to justify theistic belief to be relevant to my arguments regarding T2, the evidence for the existence of those alleged facts has to meet three conditions: (i) it is strong, (ii) it is public enough that competent contemporary theistic philosophers either are familiar with it or epistemically should be familiar with it, and (iii) a competent contemporary theistic philosopher should, once familiar with it, realize that it is strong. Conditions (ii) and (iii) are just as important as (i), since (regarding (ii)) if the evidence isn't widely available to my target group or (regarding (iii)) it is widely available but it is common to upstandingly judge it to not be strong, then it won't be detrimental to the epistemology of my target group of theistic philosophers. However, I think that even if the first condition, (i), is met, neither of the two others are met, let alone both of them.

As mentioned earlier, I am not saying that $\mathbf{T} \mathbf{2}$ and $\mathbf{T}$ are true. Even if my nine alleged facts (from section 2.1) are genuine facts, and my rebuttals to the three objectors are sound, that hardly guarantees the truth of $\mathbf{T}$. Perhaps they show that $\mathbf{T}^{*}$ is true, where $\mathbf{T}^{*}$ is just like $\mathbf{T}$ but with 'comparatively epistemically upstanding', which is tied to justification, replaced with something like 'epistemically blameless' or even 'epistemically excused', which could be (and actually are, in epistemology) given readings having little to do with justification, evidence, or warrant. I rest content with the admittedly vague two-part thesis that (i) there is good reason to accept $\mathbf{T}$ (that was the gist of 2.1) and (ii) the key objections to $\mathbf{T}$ are no good (that was the gist of 2.2).

\section{Why Responding to the Problem of Evil is so Difficult}

I just finished offering a qualified argument that contrary to many atheistic philosophers, the theistic reaction to the PoE can be epistemically upstanding even if atheism is true. Despite that, there is a sense in which the theist has no good response to the PoE even if theism is true. I will argue for that thesis in this section.

\subsection{Why Premise (c) is Key}


As I said earlier, competent theistic philosophers accept (a) from our sample PoE. Theists and nontheists alike typically accept (d) as well: God would not permit there to be unjustified suffering. ${ }^{7}$ God's justification for suffering might be opaque to us, perhaps so far beyond our cognitive powers that we cannot even fathom the form of justification involved for some cases of suffering, but it's got to be there if God really exists. Or so many theistic philosophers think.

The clear majority of theistic philosophers will accept (b) as well, as only the highly (wildly?) confident will reject it. In my judgment, denying (b) is not very plausible. If you think you know the justification for all or nearly all instances of suffering, so you are inclined to think (b) is false, the rest of this essay doesn't address your view.

Claim (b) says that the people in question have collectively failed to come to know the justification for an enormous number of instances of suffering. That is, there is an enormous number of instances of suffering $S$ such that these people have collectively failed to come to know any highly informative truth of the form 'The justification for $S$ is such-and-such'. So the emphasis is on collective knowledge. For comparison, physicists have collectively failed to come to know such-and-such claim about what dark matter is. Even if a small percentage of them truly know what dark matter is, this knowledge has not spread significantly (because of disagreement, failure of transfer of evidence, possession of misleading evidence, etc.). Hence, 'Group $\mathrm{G}$ has failed to come to know $\mathrm{X}$ but a small percentage of G's members do know $X^{\prime}$ has true instances. Similarly, even if a small percentage of theistic philosophers know the justification for all or nearly all suffering, it's not collective (because of disagreement, failure of transfer of evidence, possession of misleading evidence, etc.).

Hence, many theists find themselves rejecting (c): they hold that regardless of how hard we have tried and utterly failed to find justifications, every single instance of suffering has one anyway. What makes their view at least initially plausible is the fact that they are wisely open-minded regarding both the justifications and the largely indirect suffering-justification connections. For instance, perhaps this is part of the story of how things are:

In order for high-value goods such as certain forms of happiness to exist there have to be laws of nature that are virtually never broken (some philosophers will judge the 'unbroken' bit to be redundant). But in order to have laws of nature of that kind, horrible suffering is inevitable: not even an omni-God could avoid it. Hence, an enormous amount of the suffering in the world is linked to-in an indirect and opaque way-high-value goods such as certain kinds of happiness. It's not a simple linkage, as is the case when a specific instance of suffering (e.g. pain via a chiropractor) is coupled with a specific good such as relief from back pain. Even so, the goodness of the high-value goods outweighs the badness of the suffering connected to those laws of nature. Therefore, all that suffering is justified.

\footnotetext{
${ }^{7}$ It's arguable that theistic philosophers have been far too in awe of the omni- characterization of God. Theologians and other non-philosophers frequently find (d) implausible. For my own part, I think knowledge is far beneath God, if God exists. But my essay is not examining those groups.
} 
That is meant merely as an illustration of how subtle and indirect a justification-suffering connection might be (so you don't have to think it's correct). Some philosophers will say that the situation just described is one in which the instances of suffering involved are "outweighed by goods" (the goods being the forms of happiness) and thus morally acceptable; others will say they are morally acceptable but not "outweighed by goods" because the linkages are not of the right kind. It all depends on how one construes the use of 'coupled with' in 'the badness of instance of suffering $X$ is coupled with and outweighed by the goodness of good $Y^{\prime}$. I will not pause to enter that debate regarding direct and indirect coupling (cf. my 2013a). All that matters here is that theists tend to think that all instances of suffering are justified in some or other manner, direct or indirect, individual or collective, humanly comprehensible or humanly incomprehensible.

The reason it's so hard for theists to offer a plausible informative response to the PoE is this: it's extremely hard to find any remotely good non-theistic evidence that (c) is false even if theism is true; and yet, that's the premise she is denying.

What I mean by 'non-theistic evidence' is best explained via examples (1)-(4) in section 3.4 below.

\subsection{There Might be Good Theistic Evidence Against (c)}

In section $2 \mathrm{I}$ argued, indirectly, that there might be theistic evidence that (c) is false. Here is the recipe for compiling that alleged evidence:

Take the non-theistic evidence for (a), (b), and (d); add in the (alleged) theistic evidence for (e)experiential and, especially, testimonial; the resulting combination is (partly) theistic evidence against (c), given that the conjunction of (a), (b), (d), and (e) entails (c). How strongly that pot of evidence supports $\sim(c)$ depends, of course, on how impressive the evidence for (a), (b), (d), and (e) is.

What I'm about to argue now is that (i) there is good non-theistic evidence for (c) (that's section 3.3) and (ii) the theistic philosopher has no good evidence against (c) that is non-theistic (that's section 3.4).

\subsection{There is Good Non-Theistic Evidence for (c)}

In this subsection I'll briefly argue that we have decent non-theistic evidence for (c). In the following subsection I'll argue in detail that the non-theistic reasons contemporary philosophers have given against (c) are no good. The upshot of the two arguments is that our overall non-theistic evidence is strongly for (c)-and since it's also strongly for (a), (b), (d), and the claim that the conjunction of (a)(d) entails (e), our overall non-theistic evidence supports $\sim(e)$, which is to say it supports atheism. Of course, this doesn't mean that atheism is true or even that one's overall evidence, theistic and nontheistic, supports atheism.

It should be clear that there is good non-theistic reason to think (c) is true. To see this, it's crucial to keep in mind how modest (c) is. Given that animals who can feel both physical and emotional pain have been around on Earth for hundreds of millions of years, I estimate we are talking about at least 
a quintillion, $10^{18}$, of the hard cases of instances of suffering, the ones we have real difficulty finding justifications for. (Feel free to argue I'm off by a few orders of magnitude; it won't make any difference.) All (c) is saying is that among the quintillions of instances of suffering (give or take a few orders of magnitude) for which we have been unable to find justifications, at least one doesn't have a justification. It shouldn't be difficult to find good reason to accept this-which is not, of course, the same thing as finding a conclusive reason. Here is such good reason:

First, almost all of us who have thought long and hard about the PoE have vast knowledge of suffering and justifications for suffering: the large number of and kinds of suffering, the enormous number of and kinds of causes and effects of suffering, a great number and variety of goods, and the many connections both direct and indirect amongst suffering and goods, etc. This knowledge isn't difficult to acquire; almost any competent, intelligent, and reflective middle-aged adult has managed it. Second, a large portion of our lives is spent using this knowledge as a guide in our daily routines, and it seems to work out well enough.

A philosopher considers (a), (b), and the above two matters and then asks herself: it is the case that (a) and (b) are true but there is not even one instance of suffering that has no outweighing good? She replies negatively. That's tantamount to affirming the material conditional (c) (i.e., [(a) \& (b) \& there is no instance of suffering that has no justification]).

Hence, we have at least some moderately strong reason to think (c) is true, although of course this is not conclusive reason. In the next subsection I will argue that the alleged non-theistic evidence against (c) is no good.

\subsection{There is no Good Non-Theistic Evidence Against (c)}

Here are several facts that contemporary theistic philosophers think combine in such a way as to amount to good non-theistic evidence that (c) is false: ${ }^{8}$

1. The task of determining whether an instance of suffering has a justification can be extremely difficult and thereby generate prolonged, hardened, and reasonable disagreements about whether it is justified. For instance, there are hard questions regarding how much goodness a good has, how much badness an instance of suffering has, what it takes for a good to be appropriately connected with an instance of suffering (so as to partly or fully justify it), what connections actually exist between goods and instances of suffering, etc.

2. Moreover, there are all sorts of vitally important goods and facts about goods (e.g., their indirect and subtle connections to suffering) that even experts don't know about or that have been discovered only recently that probably apply to the suffering of humans and other creatures on earth.

\footnotetext{
${ }^{8}$ For (1) \& (2) see Alston 1991b, 1996; Durston 2000, 2005, 2006; and Howard-Snyder 1996, 2009. For (3) see Alston 1996; Wykstra 1984, 1996; and Plantinga 1988. For (4) see Alston 1991b, 1996; Bergmann 2009; and van Inwagen 1991, 2003.
} 
3. There could (epistemically anyway) be someone who was omniscient about justification and suffering. More importantly, our justification-suffering knowledge would be infinitesimal compared to the justification-suffering knowledge of such a being: she would know much, much more than we do about suffering and how it's justified.

4. We can imagine all sorts of possible scenarios consistent with all the basic facts we actually know about suffering but in which all instances of suffering are justified.

Even an open-minded atheist could, consistent with her atheism, agree that (1)-(4) are true; in that sense those claims are "non-theistic" reasons for casting doubt on (c). The question we face now is whether they collectively amount to good reason for doubting (c).

For the sake of argument I will agree that the conjunction of (1)-(4) is true; so I'm willing to meet these theistic philosophers half way. But I think that even if that conjunction is true, it fails to give any good reason to think (c) is false. That is, the truth of (1)-(4) does not give you a good reason to think 'In every single case in which we fail to find a justification for some suffering-and there are zillions of such cases, despite our best efforts over centuries-the justifications are there anyway'. As I argued earlier, there might be truly excellent theistic reason to believe that proposition! All I'm saying now is that (1)-(4) supply no such reason, contrary to many contemporary theistic philosophers (see footnote 6). In the rest of this subsection I will elaborate on this thesis regarding the evidential force of (1)-(4). I won't go in order.

Regarding (3):

Theists are fond of pointing out that God, if he exists, will have knowledge of good and evil that infinitely surpasses ours. So he would know all sorts of facts about good and evil that have entirely escaped us. This remark of Bergmann's is representative:

[T]he fact that humans can't think of any God-justifying reason for permitting an evil, doesn't make it likely that there are no such reasons; this is because if God existed, God's mind would be far greater than our minds so it wouldn't be surprising if God had reasons we weren't able to think of (Bergmann 2009; my emphasis).

I hold that the claim after 'this is because' is false. If we spell out Bergmann's point here, I think we get the following dialectic.

Theist: Imagine for a minute what it would be like to learn that there is a being $\mathrm{G}$ whose mind is a zillion times more knowledgeable than our minds.

Non-theist: Ok.

Theist: In that scenario, in which you have learned that $\mathrm{G}$ actually exists, you would not find it surprising to also learn that G's knowledge of suffering and goods is far greater than ours.

Non-theist: I agree. The topic of suffering and goods is one in which I can easily imagine that there are many truths we know nothing about. 
Theist: $\quad$ Moreover, if you would not find it surprising to learn that G's knowledge of suffering and goods is far greater than ours, then you would also not find it surprising to learn that all instances of suffering-including the ones that we haven't been able to find justifications for-are justified.

At this point the non-theist should not agree. It's easy to admit that there is a fantastic number of interesting truths about suffering and goods that we don't know at all. That's to be expected. The pretense 'What if there were a being $\mathrm{G}$ whose mind was far greater than ours?' is not necessary for making that modest admission. But that admission gives one no significant reason to think that the unknown truths about suffering and goods make it plausible that there actually are justifications in all the cases in which we couldn't find any. The key point: we can take ourselves to be excellent at judging a topic even if we admit that there are millions of truths about that topic that we know nothing about. Indeed, I don't think that's false for any instance.

To see the italicized point more clearly, consider a sports analogy:

Theist: Imagine for a minute what it would be like to learn that there is a being $\mathrm{G}$ whose mind is a zillion times more knowledgeable than our minds.

Non-theist: Ok.

Theist: In that scenario, in which you have learned that $\mathrm{G}$ actually exists, you would not find it surprising to also learn that G's knowledge of baseball is far greater than ours.

Non-theist: I agree. The topic of baseball is one in which I can easily imagine that there are many truths we know nothing about.

Theist: $\quad$ Moreover, if you would not find it surprising to learn that G's knowledge of baseball is far greater than ours, then you would also not find it surprising to learn that almost all of our comparative baseball judgments were mistaken (judgments of forms such as 'So and so was a better baseball player than the other so and so').

The conditional in the final line is false, and the reason that it's false is that we take ourselves to have pretty good judgment regarding baseball comparisons despite our admission that there are millions of truths about baseball we know nothing about. Just because I learn that some being knows infinitely more than I do about baseball, or suffering and goods, or any other topic, gives me no good reason to doubt the reliability of my judgments about baseball or suffering and goods or some other topic.

Here is another way to think about it:

- Suppose you learned that some being knew infinitely more than you do. Would that make you think you are unreliable in your comparative baseball judgments? No, of course not.

- Suppose you learned that some being knew infinitely more than you do about baseball. Would that make you think you are unreliable in your comparative baseball judgments? No, of course not. Just because you admit there are millions of baseball facts you know nothing about doesn't mean you should admit that you are unreliable in your baseball judgments. 
Similarly:

- Suppose you learned that some being knew infinitely more than you do. Would that make you think you are unreliable in your judgments about suffering and goods? No, of course not.

- Suppose you learned that some being knew infinitely more than you do about suffering and goods. Would that make you think you are unreliable in your judgments about suffering and goods? No, of course not. Just because you admit there are millions of suffering/goods facts you know nothing about doesn't mean you should admit that you are unreliable in your judgments about suffering and goods.

If you don't like the sports comparison, fine! Feel free to substitute something else for baseball. For those reasons then, I think the truth of (3) fails to provide good reason for doubting (c).

Of course, if I learned that some being knew infinitely more than I do and was perfectly good and was omnipotent, then I would think I was unreliable in my judgments about suffering and goods. I would think that I was unreliable because I would think that such a being would arrange things so that there is no gratuitous suffering. But this, of course, would be to move back into the realm of theistic reasons.

Regarding (1), (2), and (4):

Similarly, in response to (1) \& (2) one should admit that human fallibility being what it is, we have missed out on a large number of important justifications for instances of suffering. I'm sure there is a massive collection $C_{S}$ of facts about suffering that we know nothing about and that applies to the suffering we see on Earth. But so what? There is a massive collection $C_{B}$ of baseball facts that we know nothing about. The mere fact that $C_{B}$ is huge gives one no good reason to think the facts in $C_{B}$ are situated in such a way that our baseball comparisons (described above) are unreliable. ${ }^{9}$ Similarly, as far as I can see the fact that $C_{s}$ is huge gives one no good reason to think the facts in $C_{s}$ are situated in such a way that when it comes to suffering all our negatives (i.e., instances in which we have failed to find justifications) are false negatives.

For those reasons then, I don't see how (1) \& (2) work in casting serious doubt on (c). Similarly, just because it is not difficult to imagine all sorts of possible scenarios consistent with all the basic facts we actually know about suffering but in which all instances of suffering are justified, gives no good reason to think (c) is false; hence, (4) fails to appreciably support (c) as shown by a brief comparison with baseball or almost any other topic we have reliable judgments about.

\footnotetext{
${ }^{9}$ For instance, we now know that it's wrong to think that BA, RBIs, and W-L record are good indicators of baseball excellence. Facts about WAR, ERA+, OPS+, FIP, and other newly designed statistics are far superior; they are the $C_{B}$ for baseball observers from a few decades ago. Even so, those observers were highly reliable in a great many of their judgment tasks concerning baseball excellence. Just because we are better doesn't mean they were bad.
} 
My target theist needs to give us non-theistic reasons for thinking that we are truly awful at discovering the justifications for suffering; that would be a good reason to doubt (c). But if the above arguments are sound, then the non-theistic (1)-(4) aren't anywhere near good enough.

What if our knowledge of the goods-suffering linkages is unrepresentative?

I take it that philosophers agree that we collectively have a great deal of knowledge of cases in which goods are linked with instances of suffering. Those who think (c) is false hold that that knowledge is unrepresentative. How does that matter to the epistemic issues we are examining?

Pretend for a moment that a society's knowledge of the linkages between goods and cases of suffering was unrepresentative in this sense: the only goods they found to be linked with instances of suffering were purely sensory goods, such as "runner's high", the taste of champagne, orgasms, etc. More exactly, let's make four stipulations regarding this scenario. First, there are many cases in which claims of the form ' $S$ knows that instance of suffering $F$ is linked with outweighing good $G$ ' are true-although in every case $\mathrm{G}$ is a purely sensory good. Second, although there are many cases in which claims of the form ' $\mathrm{S}$ knows that instance of suffering $\mathrm{F}$ is not linked with any outweighing good' are true, in order to make the claim true the quantificational use of 'any' has to be restricted to sensory goods. Third, all instances of suffering for this society have outweighing goods. Fourth, there are many instances of suffering for them that are not outweighed by purely sensory goods (so they are outweighed by other goods).

The claim 'Even after centuries of examination, we have failed to find any outweighing goods for zillions of cases of suffering' is true for the people in that scenario. Furthermore, these people are, in a sense, quite good at spotting linkages amongst goods and instances of suffering. And yet, their knowledge of such linkages is "unrepresentative".

The thesis of this subsection is, 'We have no good non-theistic reason to think (c) is false'. The objection now being considered starts with 'But what if our knowledge of suffering and goods is unrepresentative?' So, let us ask that question of the people in our scenario: do they have good nontheistic reason to think (c) is false?

I don't see why: the mere fact that their knowledge of suffering and goods is unrepresentative fails to give them the slightest reason to think that that knowledge of theirs is unrepresentative. More to the point, if they are utterly clueless about the existence of non-sensory goods that might be linked to their suffering, if they have no good evidence that there are any such goods at all, then they would be quite reasonable in concluding that amongst the zillions of cases of suffering that they have failed to find good for, at least one is not outweighed by any good. Their conclusion would be false, by hypothesis, but it wouldn't be at all unreasonable.

Hence, when it comes to the worry about unrepresentativeness, the question for us is whether we have any good non-theistic reason to think our knowledge of the goods-suffering links is unrepresentative. For the reasons I have already given, I don't see how (1)-(4) supply any such reason. They show that our knowledge is incomplete, but that is a separate and much more modest matter. 
Is the inadequacy of (1)-(4) to cast significant doubt on (c) a surprise?

If the theist is going to appeal to non-theistic considerations in order to cast doubt worth worrying about on (c), then as any brief look at (c) will confirm, the considerations will have to be facts that make it probable that our negative results about justifications are wrong $100 \%$ of the time. This certainly looks like a tall order. As mentioned above, it's child's play to argue that our many judgments about the lack of justifications for suffering will sometimes be mistaken. Armed with that result, one can go on to argue that we will probably be mistaken about suffering significantly more often than we will be mistaken about baseball comparisons.

But the sane atheist who advocates the soundness of the (a)-(d) argument for atheism is happy to admit that when we fail to find justifications, in a large number of cases the justifications are there anyway-and she will appeal to (1) and (2) in her defense of that admission. But it's another thing entirely to argue that such false negatives are present every single time, which is what one has to do if one wants to come even close to justifying the rejection of (c). I take it that most philosophers realize that the really hard cases of suffering - the ones that are most difficult to find outweighing goods forinclude (but are not limited to) those endured by emotionally and sensorily advanced animals in the process of dying. We are talking about billions of billions of the hard cases of suffering, the ones we have real difficulty finding justifications for. By my lights, pointing out that judgments about suffering are complicated and we are ignorant of many important truths about suffering is not remotely sufficient to justify the idea that all those billions of billions of instances of suffering have justifications even though we have been unable to reveal them despite the fact that many of our best and brightest have collectively been thinking incredibly hard about the problem of evil for centuries. This is the primary reason why informatively responding to the PoE is so difficult.

So why doesn't the theistic philosopher just admit that although there are excellent reasons, Rs, for thinking all our negative results about justifications are mistaken, so (c) is false, these Rs are always theistic in the sense that they are had only by those people who already have excellent evidence/warrant for various key theistic claims, such as 'God exists and wouldn't permit unjustified suffering' or 'There is an extremely long afterlife for suffering animals with many goods and many appropriate extensive connections to earthly suffering'? Why keep insisting that non-theistic facts, such as (1)-(4), are sufficient to cast serious doubt on (c)?

Here is one answer: perhaps these philosophers think that if there is no good non-theistic reason to doubt (c) then the PoE will make disbelief in God epistemically rational for a great many people since they already have excellent evidence for (a), (b), and (d), and of course good overall evidence for (a)(d) means good overall evidence for atheism since the conjunction of (a)-(d) obviously entails atheism.

If my experience is representative-and that is a big 'if'-many atheistic philosophers are atheists due to two main causal factors: they are insufficiently aware of the testimonial cases for both theism in general and the veridicality of theistic religious experience, and they spend too much time dwelling on the irrational bases of religious belief. When the non-theistic case for (a)-(d) is added to that pot of causal factors, it's no wonder atheistic philosophers end up confident in their atheism. 
But why not just accept this result as well? Just admit that philosophically informed non-theists often (but of course not always) have available to them an argument that makes atheism highly rationalgiven their lack of evidence for theism plus lack of good evidence against any of (a)-(d). Admitting this would not of course amount to admitting that the atheistic argument is a successful proof of atheism, since one is still free to hold that it has a false premise, (c), that one can know is false provided one has certain theistic pieces of evidence ('evidence' again taken in its widest sense). By analogy, it's not hard to see how a great many false views can be warranted by those with an unfortunate evidence base.

\section{Conclusion}

As I argued in subsection 3.1, theistic philosophers typically (not always, obviously) say that their primary thesis regarding the PoE is $\sim(c)$, with most others going with $\sim(b)$ (the latter philosophers being the ones who think they know almost all of the true theodicy). In this essay I have said nothing at all regarding the truth-value of that primary thesis.

A secondary thesis of theirs, an epistemological one, is that "we" do not have good overall reason for believing (c), and that is why the argument from evil, (a)-(d), is a failure. This is the epistemological thesis that I've been targeting in section 3. I have argued that for a great number of people, who are lacking in evidence for certain theistic claims, affirming (c) is upstanding and denying it fails to be upstanding. If I'm right, then theists should modify their secondary thesis. Instead of this epistemological thesis,

We do not have good overall reason to accept (c),

they should endorse this alternative epistemological thesis:

Many intelligent and well-informed people have good overall reason to accept (c), and there probably are no strong non-theistic reasons to doubt (c); but even so, there are good theistic reasons to reject (c) that are powerful enough that persons with those theistic reasons have good overall reason to believe (c) is false. ${ }^{10}$

\section{Cited Works}

Alston, William 1991a. Perceiving God: The Epistemology of Religious Experience. Cornell University Press.

Alston, William 1991b. "The Inductive Argument from Evil and the Human Cognitive Condition." Philosophical Perspectives 5: 29-67.

Alston, William 1996. "Some (Temporarily) Final Thoughts on the Evidential Argument from Evil." The Evidential Argument from Evil. Ed. D. Howard-Snyder. Bloomington, IN: Indiana University Press. 311-32.

10 Thanks to Patrick Shirreff, Toomas Lott, and two referees for their excellent comments. 
Bergmann, Michael 2009. "Skeptical Theism and the Problem of Evil." Oxford Handbook of Philosophical Theology. Eds. T. Flint and M. Rea. New York: Oxford University Press. 374-402.

Durston, Kirk 2000. "The Consequential Complexity of History and Gratuitous Evil." Religious Studies 36: 65-80.

- - 2005. "The Failure of Type-4 Arguments from Evil." Philo 8: 109-22.

- - 2006. "The Complexity of History and Evil: A Reply to Trakakis." Religious Studies 42: 87-99.

Frances, Bryan 2019: "The Philosopher's Doom: Unreliable at Truth or Unreliable at Logic", in Ted Poston and Kevin McCain (eds.) The Mystery of Skepticism, Brill.

- - 2018c: "Philosophical Expertise", in James Chase and David Cody (eds.), The Routledge Handbook of Applied Epistemology, Routledge, 297-306.

- 2018b: "The Epistemology of Real-World Religious Disagreement Without Peers", Philosophia Christi 20 (1), 291-99.

- 2018a: "Skepticism and Disagreement", in Diego Machuca and Baron Reed (eds.), Skepticism: From Antiquity to the Present, Continuum Press.

- 2014: Disagreement, Polity Press.

- - 2013b: "Philosophical Renegades" in Jennifer Lackey and David Christensen (eds.) The Epistemology of Disagreement: New Essays, Oxford University Press, 121-66.

- - 2013a. Gratuitous Suffering and the Problem of Evil: A Comprehensive Introduction. New York: Routledge.

-- 2012: "Discovering Disagreeing Epistemic Peers and Superiors", International Journal of Philosophical Studies 20, 1-21.

- 2010: "The Reflective Epistemic Renegade" Philosophy and Phenomenological Research 8, 41963.

- 2008b: "Live Skeptical Hypotheses," John Greco (ed.) Oxford Handbook of Skepticism, 225-245.

- 2008a: "Spirituality, Expertise, and Philosophers," in Jon Kvanvig (ed.) Oxford Studies in Philosophy of Religion, v. 1, Oxford University Press, 44-81.

Frances, Bryan and Jonathan Matheson 2018: "Disagreement", Stanford Encyclopedia of Philosophy, Edward Zalta, ed.

Howard-Snyder, Daniel 1996. "The Argument from Inscrutable Evil." In his (ed.) The Evidential Argument from Evil. Bloomington, IN: Indiana University Press.

Howard-Snyder, Daniel 2009. "Epistemic Humility, Arguments from Evil, and Moral Skepticism." Oxford Studies in Philosophy of Religion. Ed. J. Kvanvig. Oxford: Oxford University Press: 17-57.

Plantinga, Alvin 2000. Warranted Christian Belief. Oxford.

Van Inwagen, Peter 1991. "The Problem of Evil, the Problem of Air, and the Problem of Silence." Philosophical Perspectives 5: Philosophy of Religion. Ed. J. Tomberlin. Atascadero, CA: Ridgeview. 135-65.

Van Inwagen, Peter 2003. The Problem of Evil. Oxford: Oxford University Press. 